\title{
Local Anesthetics Induce Human Renal Cell Apoptosis
}

\author{
H. Thomas Lee Hua Xu Cory D. Siegel Igor E. Krichevsky \\ Department of Anesthesiology, College of Physicians and Surgeons of Columbia University, New York, N.Y., USA
}

\section{Key Words}

Bupivacaine $\cdot$ Lidocaine $\cdot$ Tetracaine $\cdot$ Mitogen-activated protein kinase $\cdot$ Protein kinase $B \cdot$ Tumor necrosis factor- $\alpha$

\begin{abstract}
Renal cell apoptosis contributes significantly to the pathogenesis of acute renal failure. Local anesthetics induce apoptosis in neuronal and lymphocytic cell lines. We examined the effects of chronic $(48 \mathrm{~h}$ ) local anesthetic treatment (lidocaine, bupivacaine and tetracaine) on human proximal tubular (HK-2) cells. Apoptosis induction was assessed by detecting poly(ADP)-ribose polymerase fragmentation, caspase activation, terminal deoxynucleotidyl transferase biotin-dUTP nick end labeling (TUNEL) staining, DNA laddering and by cellular morphology. Cell death was quantified by measuring neutral red dye uptake and lactate dehydrogenase released into the cell culture medium. All 3 local anesthetics caused concentration-dependent cell death, induced HK-2 cell apoptosis and potentiated TNF- $\alpha$ induced apoptosis. Local anesthetics induced HK-2 cell apoptosis by
\end{abstract}

This work was funded by intramural grant support from the Department of Anesthesiology, Columbia University College of Physicians and Surgeons, and by National Institute of Health grant RO1 DK58547. activation of caspases 3, 6, 7, 8 and 9. ZVAD-fmk, a pancaspase inhibitor, blocked the local anesthetic induced HK-2 cell apoptosis. Local anesthetics also inhibited the activities of anti-apoptotic kinases protein kinase B (Akt) and extracellular signal regulated mitrogen-activated protein kinase. Local anesthetic's pro-apoptotic effects are independent of sodium channel inhibition as tetrodotoxin, a selective voltage-gated sodium channel blocker, failed to mimic local anesthetic-mediated induction or potentiation of HK-2 cell apoptosis. We conclude that local anesthetics induce human renal cell apoptotic signaling by caspase activation and via inhibition of prosurvival signaling pathways.

Copyright $@ 2003$ S. Karger AG, Basel

\section{Introduction}

Several clinical conditions including renal ischemic reperfusion injury, sepsis and toxic nephropathy contribute to acute renal failure [1]. Renal cell death in acute renal failure not only results from necrosis but also from apoptosis (programmed cell death) [2, 3]. In fact, acute renal failure commonly described as acute tubular necrosis is a misnomer as a significant percentage of renal cell death occurs in the form of apoptosis. It is increasingly clear that both necrotic and apoptotic cell death contribute significantly to renal dysfunction in acute renal failure $[2,3]$. The signaling pathways leading to apoptosis usually

H. Thomas Lee, MD, PhD

Department of Anesthesiology, Anesthesiology Research Laboratories Columbia University, P\&S Box 46 (PH-5), 630 West 168th Street

New York, NY 10032-3784 (USA)

Tel. +1 212305 4716, Fax +1 212305 8980, E-Mail t1128@columbia.edu 
involve the sequential activation of a family of aspartatespecific cysteine proteases, called caspases [2,3] although caspase-independent pathways have been described [4]. There are also anti-apoptotic/pro-survival signaling cascades that counteract apoptotic cell death (e.g. extracellular signaling regulated mitogen-activated protein kinase $\left(\mathrm{ERK}_{1 / 2}\right)$ and protein kinase B (PKB)) [5, 6]. Several criteria are used to characterize apoptotic changes including condensation and segregation of nuclear chromatin, cytoplasmic compaction, and the formation of apoptotic bodies. Biochemical characteristics are oligonucleosomal DNA fragmentation (into multiples of $\sim 200 \mathrm{bp}$ ), which appears on agarose gel as DNA ladders, and cleavage of distinct target proteins (e.g. poly(ADP)-ribose polymerase (PARP), laminin or gelsolin) by the activation of several caspases.

Patients with impaired preoperative renal function are at greatest risk for perioperative renal failure [1]. Local anesthetics are widely used in clinical practice, even in patients with impaired preoperative renal function. Epidural infusion of local anesthetics is routinely used for intraoperative analgesia and hemodynamic control for patients with significant risk for perioperative renal failure (e.g. patients undergoing aortovascular surgery). During induction of general anesthesia, i.v. lidocaine is given routinely to blunt sympathetic reflex to direct laryngoscopy. Local anesthetics are used to provide surgical anesthesia and analgesia in peripheral and CNS nerve blocks (spinal and epidural anesthesia). In the ICU, lidocaine is frequently used as an anti-arrythmic agent. Several studies described that local anesthetics induce apoptosis in neuronal, lymphocytic and osteoblastic cell lines [7-9]. However, it is not known whether local anesthetics cause apoptosis in human kidney cells. We aimed to determine whether local anesthetics induce apoptosis in human renal proximal tubular (HK-2) cells. We also examined the signaling mechanisms responsible for the local anesthetic-mediated induction of human renal cell apoptosis.

\section{Materials and Methods}

\section{HK-2 Cell Culture}

HK-2 cells (immortalized human proximal tubular cell line, American Type Culture Collection) were grown and passaged as described previously $[10,11]$.

\section{HK-2 Cell Treatments}

Confluent HK-2 cells were treated with increasing doses of lidocaine $(1-1,000 \mu M)$, bupivacaine $(1-300 \mu M)$ or tetracaine (1$200 \mu M$ ) for $48 \mathrm{~h}$. HK-2 cells were also treated with recombinant human TNF- $\alpha$ (25 ng/ml, Calbiochem) alone or with TNF- $\alpha$ plus lidocaine $(1-1,000 \mu M)$, bupivacaine $(1-300 \mu M)$ or tetracaine (1$200 \mu M$ ) for $48 \mathrm{~h}$ to investigate the potentiation of TNF- $\alpha$ induced apoptosis by local anesthetics. To determine whether caspases are activated by local anesthetics, some cells were pretreated with $100 \mu M$ ZVAD-fmk, a broad-spectrum caspase inhibitor, for $1 \mathrm{~h}$ prior to TNF- $\alpha$ or local anesthetic treatment. To determine whether sodium channel blockade is involved in apoptosis induction by local anesthetics, separate groups of confluent HK-2 cells were treated with increasing concentrations of tetrodotoxin $(1-2 \mu M)$, a sodiumchannel blocker, in the presence or absence of TNF- $\alpha$. TNF- $\alpha$, local anesthetics and tetrodotoxin were re-applied $24 \mathrm{~h}$ after initial treatment.

\section{Measurement of Cell Viability and Cell Injury}

Cell viability was assessed with 2 methods: (1) by neutral red dye uptake assay, and (2) by measuring LDH released into cell culture medium. Neutral red dye accumulates in the lysosomes of viable cells [12] and neutral red dye uptake assay has been compared to be equivalent to LDH leakage test and trypan blue dye uptake [13]. In preliminary studies conducted in our laboratory, we have also compared neutral red vs. trypan blue stain for assessing cell death and found them to be equivalent. After $48 \mathrm{~h}$ of treatment, HK-2 cells were exposed to $50 \mu \mathrm{g} / \mathrm{ml}$ neutral red in culture medium for $1 \mathrm{~h}$. To quantify neutral red uptake, monolayers were washed with $1 \%$ formaldehyde $/ 1 \%$ calcium chloride solution and neutral red was extracted from the cells with $1 \mathrm{ml}$ of a $1 \%$ glacial acetic acid $/ 50 \%$ ethanol solution for $15 \mathrm{~min}$ at room temperature while protected from light. The extracted dye was quantified at $540 \mathrm{~nm}$ using a spectrophotometer, and HK-2 cell viability was expressed as percent of vehicle treated cells.

Lactate dehydrogenase (LDH) released into the cell culture media was also measured as a marker of cellular injury using a commercially available colorimetric method (Promega). We determined in initial experiments that total LDH content per well in each cell culture plate was equivalent. Therefore, LDH released with local anesthetic treatment was expressed as the percent of the LDH release by the vehicletreated group within the same experiment (triplicate wells per treatment group per plate).

\section{Immunoblot Analyses}

We measured the activities of $\mathrm{ERK}_{1 / 2}$ and PKB in HK-2 cells by immunoblotting with antibodies to the phosphorylated forms of ERK $_{1 / 2}$ and PKB. We measured the extent of HK-2 cell apoptosis by detecting PARP fragmentation with immunoblotting. We also assessed activation of several caspases by detecting cleaved (active) and intact (inactive) caspases. Immunoblot analysis was performed as described previously $[10,11]$. The primary monoclonal antibodies for caspase 3, $\mathrm{pERK}_{1 / 2}$, and PARP (Santa-Cruz Biotechnologies) were diluted 1:500. The primary polyclonal phospho-PKB antibody (New England Biolabs) and primary polyclonal antibodies for caspases 6, 7 (New England Biolabs), 8, 9 (Santa-Cruz Biotechnologies) were diluted 1:1,000.

Ligase-Mediated Polymerase Chain Reaction (LM-PCR) to Detect DNA Laddering

The presence of internucleosomal DNA cleavage in HK-2 cells was detected with a commercially available LM-PCR assay kit (ApoAlert, Clontech Laboratories, Inc.), according to the manufacturer's instructions. 
In situ Terminal Deoxynucleotidyl Transferase Biotin-dUTP

Nick End Labeling (TUNEL) Assay

In situ labeling of fragmented DNA was performed with TUNEL with a commercially available in situ cell death detection kit (Roche) according to the manufacturer's instructions.

\section{Statistical Analysis}

The data were analyzed with one way analysis of variance plus Dunnett post hoc multiple comparison test to compare mean values across multiple treatment groups. In all cases, a probability statistic $<0.05$ was taken to indicate significance. All data are expressed throughout the text as mean \pm SEM.

\section{Materials}

All drugs were in saline. Unless otherwise specified, all chemicals were obtained from the Sigma Chemical Company, St. Louis, Mo., USA.

\section{Results}

We characterized HK-2 cell apoptosis by detecting PARP and caspase cleavage, DNA fragmentation, TUNEL staining, measuring cell viability and observing cellular morphology.

\section{HK-2 Cell Death by Local Anesthetics and TNF- $\alpha$}

Forty-eight-hour treatment with lidocaine caused a small, but significant, increase in LDH release compared to vehicle controls $(109 \pm 1 \%$ of vehicle treated group with $1,000 \mu M$ lidocaine, $\mathrm{n}=4, \mathrm{p}<0.05$ compared to vehicle controls, $100 \pm 2 \%, \mathrm{n}=4)$. Neutral red assay failed to detect significant loss of total HK-2 cell viability with 48-hour lidocaine treatment $(95 \pm 3 \%$ with 1,000 $\mu M$ lidocaine, $\mathrm{n}=6, \mathrm{p}>0.05$ compared to vehicle controls, $100+3 \%, n=6)$. However, lidocaine induced apoptotic changes in HK-2 cells with detectable PARP and DNA fragmentations and activation of caspases (see below), suggesting that LDH assay is a more sensitive indicator of cellular injury compared to the neutral red assay method. Bupivacaine and tetracaine (shown in figure 1 as a representative local anesthetic), more potent local anesthetics, caused concentration-dependent increase in LDH release (e.g. $119 \pm 2 \%$ and $135 \pm 4 \%$ of vehicle controls, $n=4, p<0.05$ ) and decrease in HK-2 cell viability (neutral red dye uptake of $89 \pm 1 \%$ and $32 \pm 5 \%$ of vehicle controls, $\mathrm{n}=6, \mathrm{p}<0.05$ ) after $48 \mathrm{~h}$ treatment with $300 \mu M$ bupivacaine and $200 \mu M$ tetracaine (fig. 1), respectively. Treatment with TNF- $\alpha(25 \mathrm{ng} / \mathrm{ml}$ for $48 \mathrm{~h})$ also caused significant increase in LDH release $(130 \pm$ $4 \%$ of vehicle controls, $n=4, p<0.05$ ) and loss of HK-2 cell viability (neutral red dye uptake of $74 \pm 4 \%$ of vehicle controls, $n=6, p<0.05$ ). Co-incubation of local anes-

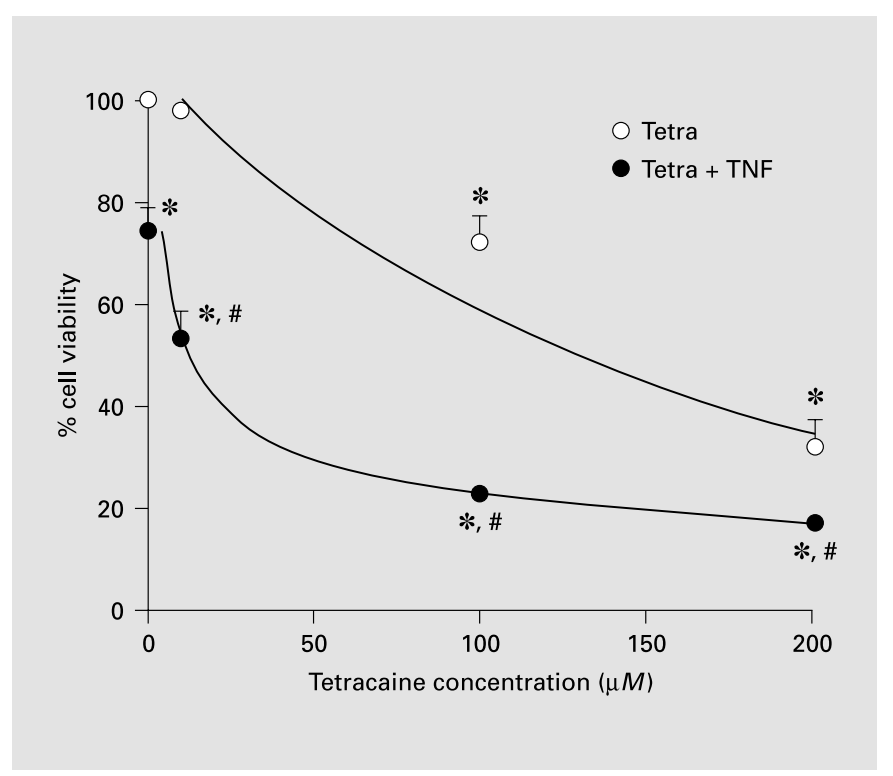

Fig. 1. Tetracaine-induced HK-2 cell death as assessed by neutral red staining assay. Percent cell death correlate with percent reduction in neutral red dye uptake of each group compared to the vehicle treated control HK-2 cells. Forty-eight hours of tetracaine $(n=6)$ treatment caused concentration-dependent potentiation of TNF- $\alpha$-induced HK- 2 cell death. Moreover, $48 \mathrm{~h}$ tetracaine treatment caused concentration-dependent HK- 2 cell death. $* \mathrm{p}<0.05$ vs. vehicle treated control cells. \# $\mathrm{p}<0.05$ vs. TNF- $\alpha$ treated cells. Error bars represent 1 SEM.

thetics with TNF- $\alpha$ significantly potentiated the release of LDH $(110 \pm 2 \%, 115 \pm 3 \%$, and $138 \pm 4 \%$ of vehicle+TNF- $\alpha$ controls, $n=6, p<0.05)$ and the loss of HK-2 cell viability $(47 \pm 9 \%, 16 \pm 1 \%$, and $18 \pm 1 \%$ of vehicle + TNF- $\alpha$ controls, $n=6, p<0.05$ ) after 48 h treatment with $500 \mu M$ lidocaine+TNF- $\alpha, 300 \mu M$ bupivacaine+TNF- $\alpha$, and $200 \mu M$ tetracaine+TNF- $\alpha$ (fig. 1), respectively.

Figure 2 shows representative morphological changes following 48-hour treatment with saline vehicle (fig. 2a), TNF- $\alpha$ ( $25 \mathrm{ng} / \mathrm{ml}$, fig. $2 b)$, lidocaine (500 $\mu M$, fig. $2 \mathrm{c})$, bupivacaine $(300 \mu M$, fig. $2 \mathrm{~d})$ or tetracaine $(200 \mu M$, fig. 2e). The proportion of dead cells as judged by cell morphology (cell shrinkage and rounding up, membrane blebbing) increased with TNF- $\alpha$ and local anesthetic treatments. Tetracaine induced the most HK-2 cell loss and detachment, consistent with the neutral red assay. Local anesthetic (tetracaine shown) induced HK-2 cell morphology changes and cell loss was prevented with a caspase inhibitor, ZVAD-fmk (100 $\mu M$ pretreatment for $1 \mathrm{~h}$, fig. 2F). 

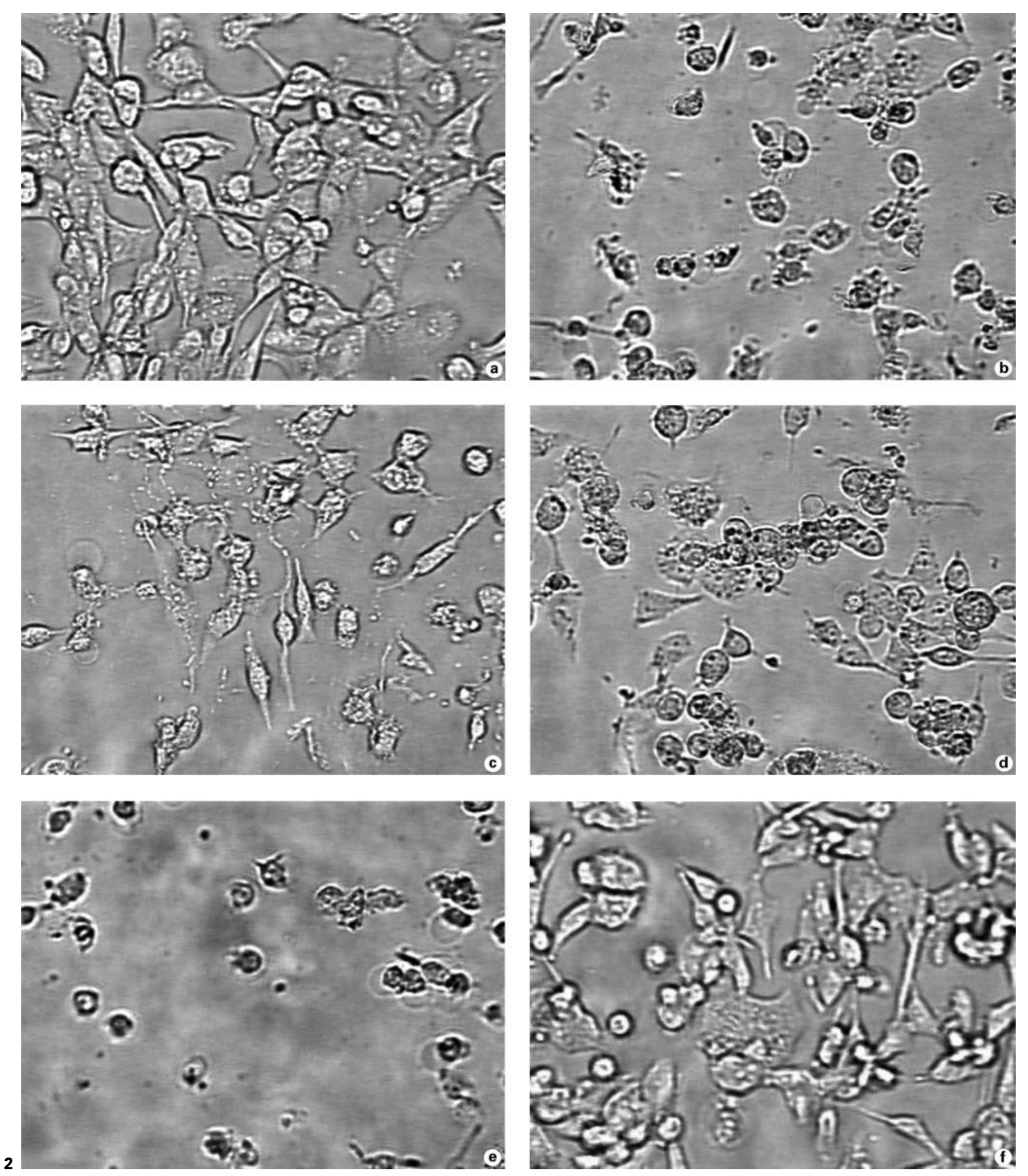


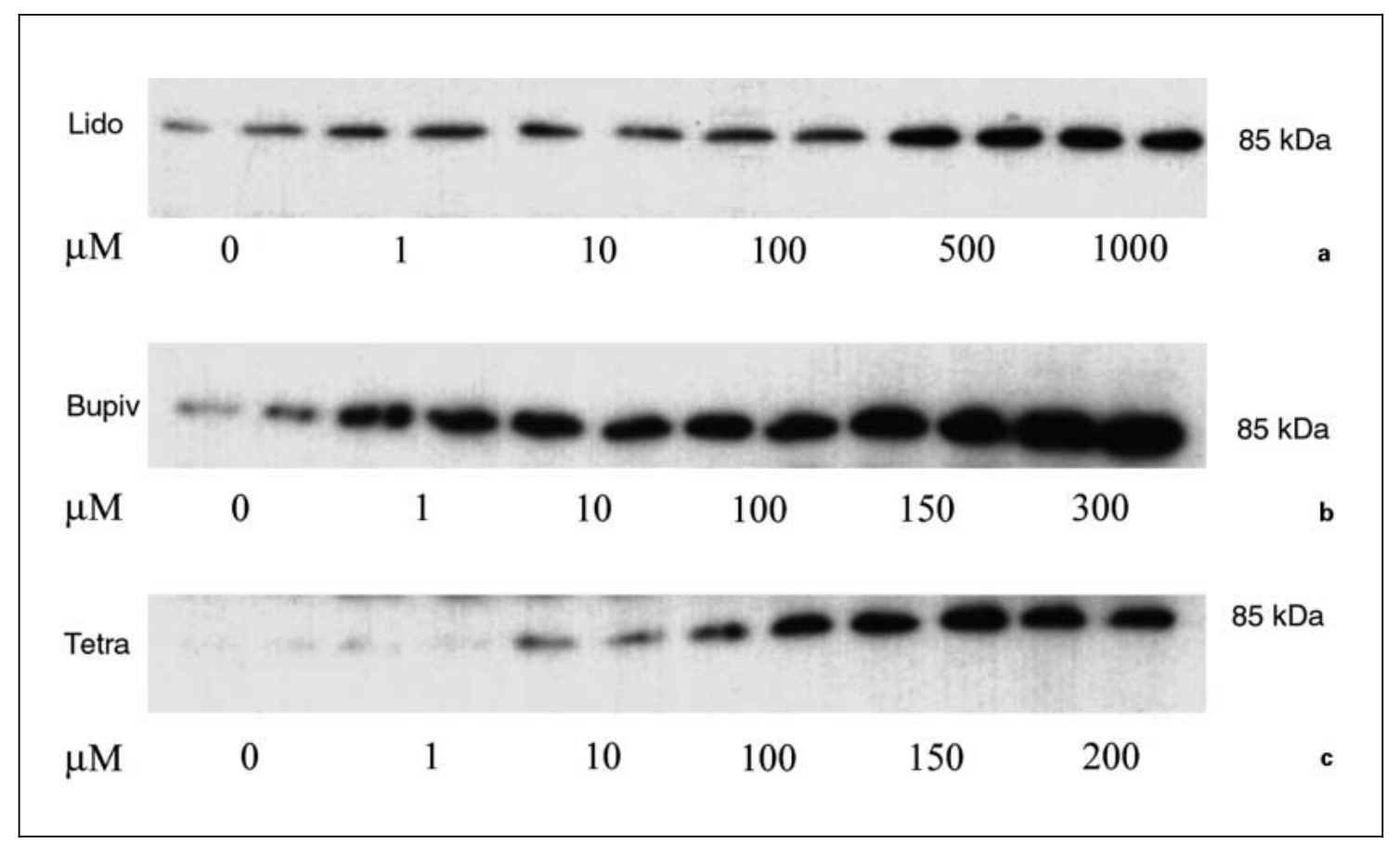

Fig. 3. Local anesthetics induce HK-2 cell apoptosis detected by PARP fragmentation. Forty-eight hours of lidocaine $(\mathbf{a}, n=4)$, bupivacaine $(\mathbf{b}, n=4)$ and tetracaine $(\mathbf{c}, n=4)$ treatment caused concentration-dependent increase in PARP fragmentation compared to vehicle treated control HK-2 cells. a-c show, in duplicate per dose, the predominant 85-kD PARP fragments with increasing doses of local anesthetic.

\section{HK-2 Cell Apoptosis Induction and Potentiation by \\ Local Anesthetics}

PARP Fragmentation. As expected, $48 \mathrm{~h}$ of incubation with $25 \mathrm{ng} / \mathrm{ml}$ of TNF- $\alpha$ caused fragmentation of $115 \mathrm{kD}$ PARP (a substrate of caspases) into 85-kD fragments (291 $\pm 34 \%, \mathrm{n}=4$ ) compared to the vehicle treated controls $(100 \pm 4 \%, n=4, p<0.05)$. Forty-eight hours of lidocaine, bupivacaine or tetracaine treatment also caused concentration-dependent increase in PARP fragmentation (e.g. $294 \pm 63 \%, 208 \pm 9 \%$ and $721 \pm 118 \%$ of vehicle controls, $\mathrm{n}=4, \mathrm{p}<0.05$ with $500 \mu M$ lidocaine, $300 \mu M$ bupivacaine, and $200 \mu M$ tetracaine, respectively) (fig. 3). In addition, when co-incubated with TNF- $\alpha$, all 3 local anesthetics caused concentration-dependent potentiation of TNF- $\alpha$ induced PARP fragmentation in HK-2 cells (e.g. $164 \pm 21 \%, 491 \pm 15 \%$ and $219 \pm 22 \%$

Fig. 2. Representative morphological $(100 \times)$ changes following $48 \mathrm{~h}$ treatment with saline vehicle (a), TNF- $\alpha(25 \mathrm{ng} / \mathrm{ml}$, b), lidocaine $(500 \mu M, \mathbf{c})$, bupivacaine $(300 \mu M, \mathbf{d})$ or tetracaine $(200 \mu M, \mathbf{e})$. Tetracaine-induced HK-2 cell morphology change and cell loss was prevented with ZVAD-fmk (100 $\mu M$ pretreatment for $1 \mathrm{~h}, \mathbf{f})$. of TNF- $\alpha$ induced PARP fragmentation $(100 \pm 9 \%), \mathrm{n}=$ $4, \mathrm{p}<0.05$ after $48 \mathrm{~h}$ treatment with $500 \mu M$ lidocaine+TNF- $\alpha, 300 \mu M$ bupivacaine+TNF- $\alpha$, and $200 \mu M$ tetracaine+TNF- $\alpha$, respectively) (fig. 4).

TUNEL Assay. The number of TUNEL-positive cells (reflecting increased DNA nicking with induction of apoptosis) was determined from 5 separate fields (4 corners and the center, $200 \times$ ) for each slide. Control HK-2 cells had very few TUNEL-positive cells per slide (average of $2 \pm 1 \%$ TUNEL-positive cells per field, $n=8$ ). Fortyeight hour treatment with TNF- $\alpha$ increased HK-2 cell apoptosis detected by the TUNEL assay (average of $72 \pm$ $14 \%$ TUNEL-positive cells per slide, $\mathrm{n}=6, \mathrm{p}<0.05$ vs. vehicle controls). Moreover, lidocaine $(500 \mu M)$, bupivacaine $(300 \mu M)$ and tetracaine $(200 \mu M)$ treatment for $48 \mathrm{~h}$ also increased the number of TUNEL-positive cells (average of $22 \pm 6 \%, \mathrm{n}=6,38 \pm 9 \%, \mathrm{n}=5$, and $59 \pm$ $15 \%, \mathrm{n}=4$, TUNEL-positive cells per slide, respectively, $\mathrm{p}<0.05$ vs. vehicle controls).

$D N A$ Laddering. Figure 5 shows a representative DNA ladder formation on $2 \%$ agarose gel electrophoresis $(n=4$ experiments). Forty-eight-hour treatment with TNF- $\alpha$ $(25 \mathrm{ng} / \mathrm{ml})$, lidocaine $(500 \mu M)$, bupivacaine $(300 \mu M)$ 




Fig. 4. Local anesthetics potentiate TNF- $\alpha$ induced HK-2 cell apoptosis detected by PARP fragmentation. Forty-eight hours of lidocaine $(\mathbf{a}, \mathrm{n}=4)$, bupivacaine $(\mathbf{b}, \mathrm{n}=4)$ and tetracaine $(\mathbf{c}, \mathrm{n}=4)$ co-incubation with TNF- $\alpha$ caused concentration-dependent increase in PARP fragmentation compared to TNF- $\alpha(25 \mathrm{ng} / \mathrm{ml})$ treated HK-2 cells. a-c show the predominant $85-\mathrm{kD}$ PARP fragments with increasing doses of local anesthetic (first two lanes represent TNF- $\alpha$ treated group in duplicate).

Fig. 5. A representative $2 \%$ agarose gel electrophoresis demonstrating formation of DNA ladders after local anesthetic treatment. Control HK-2 cells (C) display a very faint DNA laddering. In contrast, 48-hour treatment with TNF- $\alpha(25 \mathrm{ng} / \mathrm{ml})$, lidocaine (L, $500 \mu M)$, bupivacaine (B, $300 \mu M)$ and tetracaine $(\mathrm{T}, 200 \mu M)$ induced prominent DNA laddering composed of multiples of $\sim 200$ bp (a characteristic hallmark feature of apoptosis). $\mathrm{M}=$ DNA molecular weight marker in basepairs.

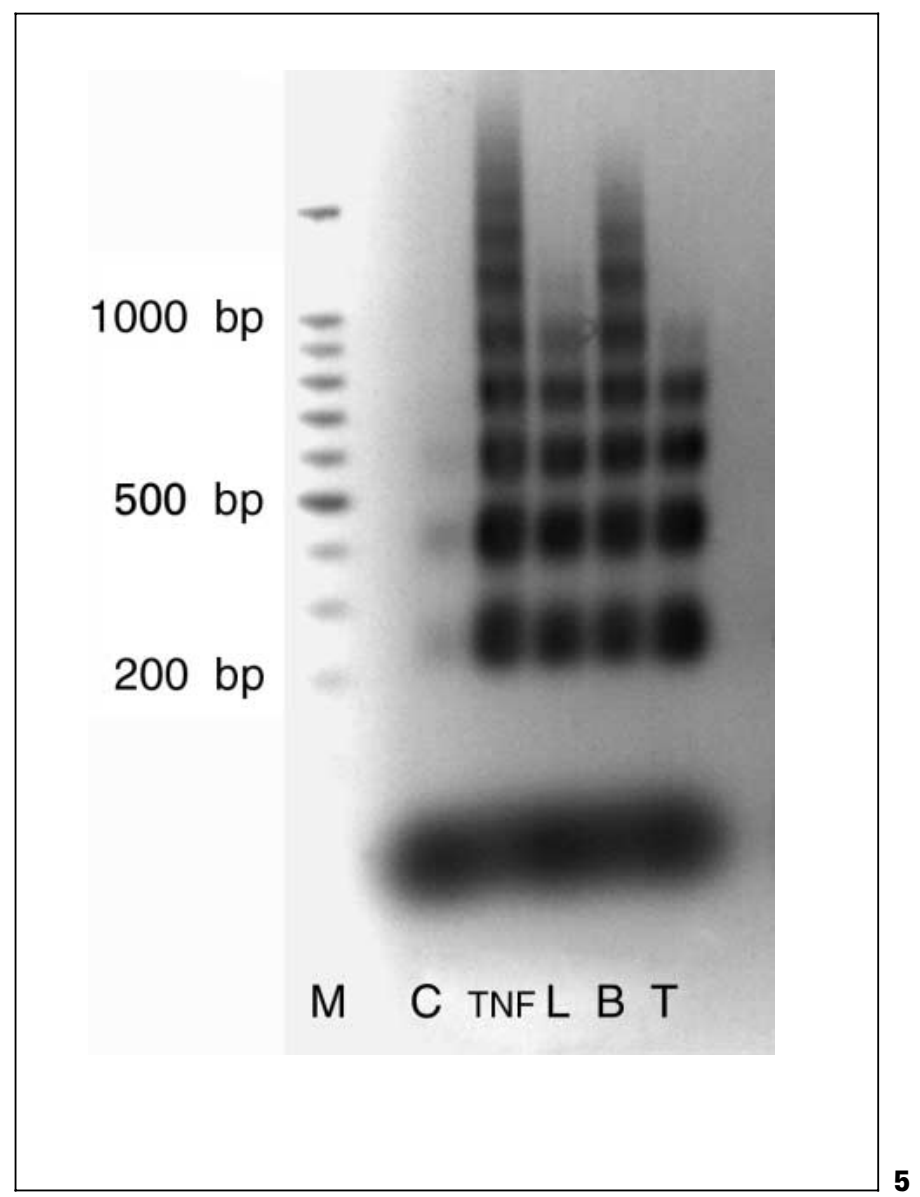


Fig. 6. Influence of local anesthetics on prosurvival/anti-apoptotic signaling pathways ERK $_{1 / 2}$ and PKB. a, b Shown, in duplicate, are representative phospho-ERK $\mathrm{K}_{1 / 2}$ and phospho-PKB bands after $48 \mathrm{~h}$ treatment with lidocaine (Lido, $500 \mu M$ ), bupivacaine (Bupiv, 200 $\mu M$ ) and tetracaine (Tetra, $200 \mu M)$. c Concentration-dependent inhibition of phosphorylated ERK2 and PKB in response to tetracaine as a representative local anesthetic. $* p<0.05$ vs. vehicletreated control cells. Error bars represent 1 SEM.



and tetracaine $(200 \mu M)$ induced prominent DNA laddering composed of multiples of $\sim 200 \mathrm{bp}$.

\section{Role of Sodium Channels in HK-2 Cell Apoptosis}

Tetrodotoxin $(1 \mathrm{n} M-2 \mu M)$ failed to mimic the local anesthetic mediated induction $(\mathrm{n}=4)$ and potentiation $(n=4)$ of apoptosis in HK-2 cells (detected with PARP fragmentation and DNA laddering) (data not shown).

\section{Effects on Anti-Apoptotic/Pro-Survival Signaling}

With immunoblotting using phospho-specific antisera against $\mathrm{pERK}_{1 / 2}$ and $\mathrm{pPKB}$, we determined that $48 \mathrm{~h}$ treatment with lidocaine, bupivacaine and tetracaine caused concentration-dependent inhibition of $\mathrm{ERK}_{1 / 2}$ and PKB activity (data not shown). Forty-eight hours' treatment with lidocaine $(500 \mu M$; fig. 6) decreased the intensities of $\mathrm{ERK}_{2}$ and $\mathrm{PKB}$ phosphorylation (reflecting the activities of these enzymes) to $67 \pm 5 \%(\mathrm{n}=4, \mathrm{p}<$ $0.05)$ of controls $(100 \pm 2 \%, n=4)$ and $40 \pm 10 \%(n=4$, $\mathrm{p}<0.05)$ of controls $(100 \pm 3 \%, \mathrm{n}=4)$, respectively. Treatment with bupivacaine $(300 \mu M$; fig. 6) decreased the intensities of $\mathrm{ERK}_{2}$ and PKB phosphorylation to 59 $\pm 5 \%(\mathrm{n}=4, \mathrm{p}<0.05)$ of controls $(100 \pm 2 \%, \mathrm{n}=4)$ and $40 \pm 10 \%(\mathrm{n}=4, \mathrm{p}<0.05)$ of controls $(100 \pm 6 \%, \mathrm{n}=4)$, respectively. Tetracaine treatment $(200 \mu M$; fig. 6$)$ decreased the intensities of $\mathrm{ERK}_{2}$ MAPK and PKB phosphorylation to $45 \pm 11 \%(\mathrm{n}=4, \mathrm{p}<0.05)$ of controls $(100$ $\pm 2 \%, \mathrm{n}=4)$ and $54 \pm 2 \%(\mathrm{n}=4, \mathrm{p}<0.05)$ of controls 


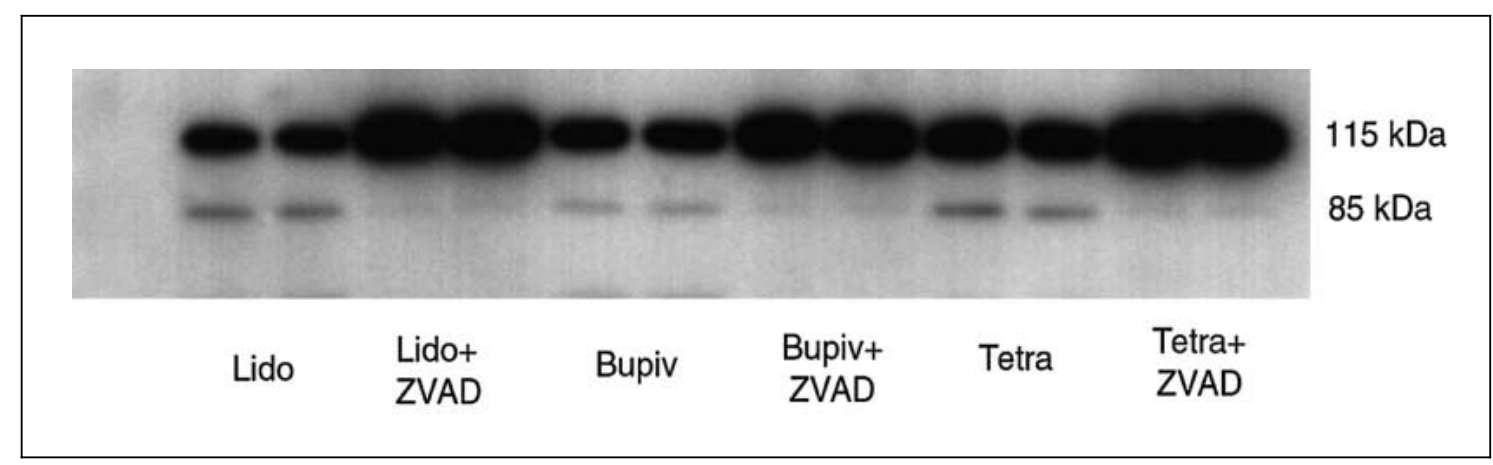

Fig. 7. Caspases are involved in local anesthetic mediated induction of apoptosis and PARP fragmentation. A representative ( $\mathrm{n}=2$ shown) immunoblot of PARP fragmentation after 48-hour treatment with lidocaine (Lido, $500 \mu M)$, bupivacaine (Bupiv, $200 \mu M$ ) and tetracaine (Tetra, $200 \mu M$ ) in the presence and absence of ZVAD-fmk (ZVAD, a pan-caspase inhibitor, $100 \mu M)$. PARP fragmentation was inhibited by ZVAD-fmk.

$(100 \pm 4 \%, n=4)$, respectively. Similar reductions in $\mathrm{ERK}_{1}$ activity were also observed (data not shown).

\section{Role of Caspases in Local Anesthetic-Induced Apoptosis}

ZVAD-fmk $(100 \mu M)$, a broad-spectrum inhibitor of caspases, inhibited local anesthetic-mediated induction of apoptosis as evidenced by preservation of cell viability after $48 \mathrm{~h}$ tetracaine $(200 \mu M$; fig. $2 \mathrm{f})$ treatment and also by inhibition of PARP fragmentation (fig. 7). Moreover, ZVAD-fmk abolished both TNF- $\alpha$-induced apoptosis and local anesthetic-induced potentiation of HK-2 cell apoptosis (data not shown).

Procaspases are cleaved into activated fragments during apoptosis induction and execution. With immunoblotting, we detected the cleavage of several pro-caspases with local anesthetic treatments. Caspases 3, 6, 7, 8 and 9 were cleaved after $48 \mathrm{~h}$ treatment of HK-2 cells with lidocaine $(500 \mu M)$, bupivacaine $(300 \mu M)$ and tetracaine $(200 \mu M)$ (fig. 8).

\section{Discussion}

Our major findings in this study are that local anesthetics induced human kidney proximal tubule (HK-2) cell apoptosis by activation of caspases and via inhibition of pro-survival signaling kinases $\mathrm{ERK}_{1 / 2}$ and PKB. In addition, local anesthetics potentiated TNF- $\alpha$-induced HK-2 cell apoptosis. Interestingly, although the pro-apoptotic properties of local anesthetics are independent of voltage gated sodium channel blockade, the potency of apoptosis induction correlates with potency and toxicity of local anesthetics described in vivo [14].

Our study is the first report to describe that local anesthetics induce and potentiate apoptosis in human kidney proximal tubule cells. In this study, we utilized HK-2 cells to study in vitro effects of local anesthetics on human proximal tubule cells. HK-2 cells are immortalized adult human proximal tubular cells transfected with E6/E7 genes of a human papilloma virus (HPV 16) [15]. Transfection with HPV16 has been shown to immortalize epithelial cells of diverse origin without significantly altering their phenotype or function. HK-2 cells have been shown to retain the phenotypic expression and functional characteristics of human proximal tubules [15]. Extensive studies have utilized HK-2 cells to study in vitro renal physiology and pathology [16-19]. Moreover, HK-2 cells have been studied as an in vitro model of renal apoptosis induction with multiple stimuli including oxidative stress [20], Shiga toxin [21] and sustained hypo-osmotic stress [22].

All of the local anesthetics utilized in this study induced concentration-dependent apoptotic changes in HK-2 cells. Apoptosis signaling can be divided into induction, execution and degradation phases [2, 3]. Moreover, apoptosis induction is a dynamic process and the cell may remain viable until the degradation phase of apoptosis. Although $48 \mathrm{~h}$ of lidocaine treatment induced easily measurable apoptotic signaling in HK-2 cells (e.g. DNA laddering, PARP fragmentation), increase in LDH release was very modest. In contrast, 48-hour treatment with bupivacaine and tetracaine, more potent local anesthetics, resulted in significantly higher HK-2 cell death by 


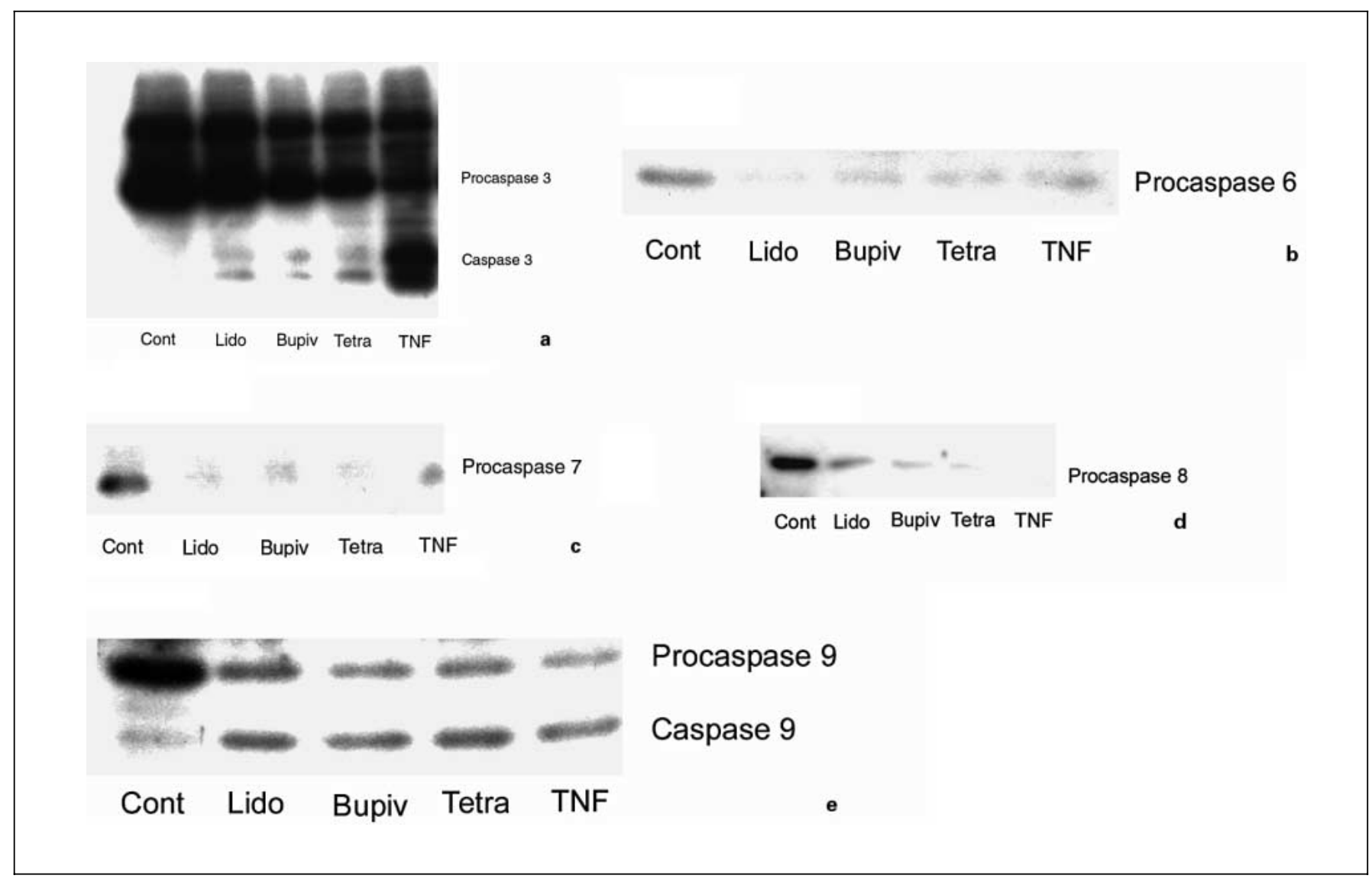

Fig. 8. Forty-eight hours of treatment with local anesthetics activates caspases as demonstrated by cleavage of inactive procaspases into activated caspases. Representative immunoblottings demonstrate that procaspases 3 (a), 6 (b), 7 (c), 8 (d) and 9 (e) were cleaved after $48 \mathrm{hr}$ treatment of HK-2 cells with lidocaine (Lido, $500 \mu M$ ), bupivacaine (Bupiv, $200 \mu M$ ) and tetracaine (Tetra, $200 \mu M$ ). TNF- $\alpha$-induced caspase activation is also shown.

apoptosis. Therefore, we show that tetracaine was the most potent inducer of HK-2 cell apoptosis and lidocaine was the least potent. When we treated human airway smooth muscle cells with varying concentrations of lidocaine, bupovaciane and tetracaine, we failed to detect apoptotic changes [unpubl. obs.]. This demonstrates that apoptosis induction by local anesthetics is not a generalized phenomenon, but is a cell-type-specific event. Moreover, the toxicity of local anesthetics observed in vitro correlates well with in vivo potency and toxicity.

$\mathrm{ERK}_{1 / 2}$ and PKB mediate cell growth, translate survival signals and counteract apoptotic signaling cascade [5]. In this study, the effects of local anesthetics on these antiapoptotic signaling cascades were examined with phospho-specific antisera against $\mathrm{ERK}_{1 / 2}$ and PKB. The level of phosphorylation of these intracellular signaling proteins correlates with their activity [23]. Local anesthetics concentration-dependently inhibited $\mathrm{ERK}_{1 / 2}$ and $\mathrm{PKB}$ activity in HK-2 cells. Similarly, in PC12 cells derived from rat pheochromocytoma, local anesthetics inhibited $\mathrm{M}_{3}$ muscarinic acetylcholine receptor mediated activation of ERK $\mathrm{E}_{1 / 2}$ independent of sodium channel blockade [24]. We have demonstrated in HK-2 cells that inhibition of MEK-1/ERK and PI3-kinase/PKB pathways with PD98059 and wortmanin, respectively, lead to increased HK-2 cell apoptosis [25].

The mechanism of local anesthetic-mediated inhibition of $E K_{1 / 2}$ and PKB remains to be determined. Although the blockade of sodium channels is the proposed mode of action of local anesthetics utilized in clinical practice [26], we conclude that induction of pro-apoptotic signaling by local anesthetics is independent of sodium channel blockade as tetrodotoxin failed to mimic the local anesthetic-mediated induction of HK-2 cell apoptosis. It 
is of interest to note that the rank order potency of cytotoxicity in our study correlates well with the in vivo potency and toxicity of local anesthetics [14]. This implies that the rank order of potency of cellular effect of local anesthetics can be applied to beyond that of sodium channel inhibition.

Recent studies have demonstrated alternative cellular actions of local anesthetics. Local anesthetics inhibit voltage gated calcium and potassium channels $[27,28]$ and ATP-sensitive potassium channels [29]. Local anesthetics have inhibitory effects on G-protein coupled receptors such as thromboxane $\mathrm{A}_{2}$ [30], $\mathrm{M}_{1}$ and $\mathrm{M}_{3}$ muscarinic [31, 32] and LPA [33] receptors. Xiong et al. demonstrated inhibition of $G_{i}$ protein-mediated modulation of potassium and calcium currents by local anesthetics in rat anterior pituitary cells [34]. Such inhibition of G-protein pathways may have pro-apoptotic/anti-survival effects on HK-2 cells as $G_{i}$ protein pathway is coupled to activation of PI3-kinase/PKB and ERK $\mathrm{E}_{1 / 2}$ in HK-2 cells. We have demonstrated that inhibition of $\mathrm{G}_{\mathrm{i}}$ protein with pertussis toxin-induced apoptosis in HK-2 cells [25].

In addition to inhibiting pro-survival signaling kinases PKB and ERK $_{1 / 2}$, local anesthetics induced HK-2 cell apoptosis by activation of caspases. Caspases are expressed as inactive pro-enzymes in living cells and become activated by proteolytic processing at internal aspartate residues [35]. Caspase activation cascade results in sequential protein cleavage (e.g. PARP) and DNA fragmentation. Pro-apoptotic signals activate initiator caspases (e.g. caspases 8, 9, and 10) that, in turn, cleave and activate effector caspases (e.g. caspases 3, 6 and 7) to orchestrate the morphological and biochemical features of apoptosis. We showed that a pan-caspase inhibitor ZVAD-fmk prevented both TNF- $\alpha$ - and local anestheticmediated induction of HK-2 cell apoptosis. We also dem- onstrate the activation of two major initiator caspases (caspases 8 and 9) and 3 effector caspases (caspases 3, 6 and 7) with local anesthetics. However, we did not demonstrate that local anesthetics directly activate caspases. Caspases may also be indirectly activated by changes in upstream regulator activities including PKB and ERK.

We show in this study that local anesthetics potentiate TNF- $\alpha$-mediated apoptosis in HK-2 cells. TNF- $\alpha$, a proinflammatory cytokine, induces apoptosis in many cell types including renal tubular epithelial cells by interacting with specific membrane bound TNF receptors [36, 37]. Circulating TNF- $\alpha$ increases in many pathophysiological conditions including sepsis, renal failure and cardiopulmonary bypass and is considered to be a key mediator in the generation of renal IR injury and septic shock [36].

We used a wide range of local anesthetic concentration for our in vitro study $(1-1,000,1-300$ and $1-200 \mu M$ for lidocaine, bupivacaine and tetracaine, respectively). Plasma and interstitial concentrations of local anesthetics ranges from 5-20 $\mu M$ after intravenous [38, 39] and epidural $[40,41]$ injections to $1-10 \mathrm{~m} M$ range [42] after local nerve plexus infiltrations (e.g. interscalene or axillary block). Although we recognize that it is impossible to extrapolate in vitro drug concentrations to an in vivo setting, we demonstrate concentration-dependent induction of apoptosis signaling by 3 local anesthetics over a wide range of concentrations.

In conclusion, clinically utilized local anesthetics (lidocaine, bupivacaine and tetracaine) induced apoptosis in human kidney proximal tubule cells by caspase activation and via inhibiting pro-survival/anti-apoptotic protein kinases $\mathrm{ERK}_{1 / 2}$ and PKB. Apoptosis induction by local anesthetic is independent of voltage gated sodium channel blockade. Studies are underway to extend our in vitro findings to in vivo experiments.

\section{References}

1 Star RA: Treatment of acute renal failure. Kidney Int 1998;54:1817-1831.

2 Rana A, Sathyanarayana P, Lieberthal W: Role of apoptosis of renal tubular cells in acute renal failure: Therapeutic implications. Apoptosis 2001;6:83-102.

3 Lieberthal W, Koh JS, Levine JS: Necrosis and apoptosis in acute renal failure. Semin Nephrol 1998;18:505-518.

4 Daugas E, Nochy D, Ravagnan L, Loeffler M, Susin SA, Zamzami N, Kroemer G: Apoptosisinducing factor (AIF): An ubiquitous mitochondrial oxidoreductase involved in apoptosis. FEBS Lett 2000;476:118-123.
5 Buckley S, Driscoll B, Barsky L, Weinberg K, Anderson K, Warburton D: ERK activation protects against DNA damage and apoptosis in hyperoxic rat AEC2. Am J Physiol 1999;277: L159-L166.

6 Xia Z, Dickens M, Raingeaud J, Davis RJ, Greenberg ME: Opposing effects of ERK and JNK-p38 MAP kinases on apoptosis. Science 1995;270:1326-1331.

7 Arita K, Utsumi T, Kato A, Kanno T, Kobuchi $\mathrm{H}$, Inoue B, Akiyama J, Utsumi K: Mechanism of dibucaine-induced apoptosis in promyelocytic leukemia cells (HL-60). Biochem Pharmacol 2000;60:905-915.
8 Nakamura K, Kido H, Morimoto Y, Morimoto H, Kobayashi S, Morikawa M, Haneji T: Prilocaine induces apoptosis in osteoblastic cells. Can J Anaesth 1999;46:476-482.

9 Kim M, Lee YS, Mathews HL, Wurster RD: Induction of apoptotic cell death in a neuroblastoma cell line by dibucaine. Exp Cell Res 1997;231:235-241.

10 Lee HT, Emala C: Adenosine attenuates oxidant injury in human kidney proximal tubular cells via $\mathrm{A} 1$ and $\mathrm{A} 2 \mathrm{a}$ adenosine receptor activation. Am J Physiol Renal Physiol 2002;282: F844-F852. 
11 Lee HT, Emala CW: Characterization of adenosine receptors in human kidney proximal tubule (HK-2) cells. Exp Nephrol 2002; in press.

12 Weber TJ, Monks TJ, Lau SS: PGE2-mediated cytoprotection in renal epithelial cells: Evidence for a pharmacologically distinct receptor. Am J Physiol 1997;273:F507-F515.

13 Zhang SZ, Lipsky MM, Trump BF, Hsu IC: Neutral red (NR) assay for cell viability and xenobiotic-induced cytotoxicity in primary cultures of human and rat hepatocytes. Cell Biol Toxicol 1990;6:219-234.

14 Liu P, Feldman HS, Covino BM, Giasi R, Covino BG: Acute cardiovascular toxicity of intravenous amide local anesthetics in anesthetized ventilated dogs. Anesth Analg 1982;61: 317-322.

15 Ryan MJ, Johnson G, Kirk J, Fuerstenberg SM, Zager RA, Torok-Storb B: HK-2: An immortalized proximal tubule epithelial cell line from normal adult human kidney. Kidney Int 1994;45:48-57.

16 Zager RA, Schimpf BA, Gmur DJ, Burke TJ: Phospholipase A2 activity can protect renal tubules from oxygen deprivation injury. Proc Natl Acad Sci USA 1993;90:8297-8301.

17 Iwata M, Herrington J, Zager RA: Protein synthesis inhibition induces cytoresistance in cultured human proximal tubular (HK-2) cells. Am J Physiol 1995;268:F1154-F1163.

18 Zager RA: Calcitriol directly sensitizes renal tubular cells to ATP-depletion- and iron-mediated attack. Am J Pathol 1999;154:1899_ 1909.

19 Zager RA, Iwata M: Inorganic fluoride: Divergent effects on human proximal tubular cell viability. Am J Pathol 1997;150:735-745.

20 Cuttle L, Zhang XJ, Endre ZH, Winterford C, Gobe GC: Bcl-X(L) translocation in renal tubular epithelial cells in vitro protects distal cells from oxidative stress. Kidney Int 2001;59: 1779-1788

21 Sood A, Mathew R, Trachtman H: Cytoprotective effect of curcumin in human proximal tubule epithelial cells exposed to shiga toxin. Biochem Biophys Res Commun 2001;283:3641.
22 Jackle T, Hasel C, Melzner I, Bruderlein S, Jehle PM, Moller P: Sustained hyposmotic stress induces cell death: Apoptosis by defeat. Am J Physiol Cell Physiol 2001;281:C1716C1726.

23 Dickenson JM, Blank JL, Hill SJ: Human adenosine A1 receptor and P2Y2-purinoceptor-mediated activation of the mitogen-activated protein kinase cascade in transfected CHO cells. Br J Pharmacol 1998;124:14911499.

24 Tan Z, Dohi S, Ohguchi K, Nakashima S, Nozawa Y: Local anesthetics inhibit muscarinic receptor-mediated activation of extracellular signal-regulated kinases in rat pheochromocytoma PC12 cells. Anesthesiology 1999;91: 1014-1024.

25 Lee HAT, Emala CW: Adenosine receptor modulation of human renal cell apoptosis. Anesthesiology 2001;95:A407.

26 Butterworth JF, Strichartz GR: Molecular mechanisms of local anesthesia: A review. Anesthesiology 1990;72:711-734.

27 Castle NA: Bupivacaine inhibits the transient outward $\mathrm{K}^{+}$current but not the inward rectifier in rat ventricular myocytes. J Pharmacol Exp Ther 1990;255:1038-1046.

28 Josephson IR: Lidocaine blocks $\mathrm{Na}, \mathrm{Ca}$ and $\mathrm{K}$ currents of chick ventricular myocytes. J Mol Cell Cardiol 1988;20:593-604.

29 Yoneda I, Sakuta H, Okamoto K, Watanabe Y: Effects of local anesthetics and related drugs on endogenous glibenclamide-sensitive $\mathrm{K}^{+}$channels in Xenopus oocytes. Eur J Pharmacol 1993;247:267-272.

30 Kohrs R, Hoenemann CW, Feirer N, Durieux ME: Bupivacaine inhibits whole blood coagulation in vitro. Reg Anesth Pain Med 1999;24: 326-330.

31 Hollmann MW, Ritter CH, Henle P, de Klaver M, Kamatchi GL, Durieux ME: Inhibition of $\mathrm{m} 3$ muscarinic acetylcholine receptors by local anaesthetics. Br J Pharmacol 2001;133:207216.

32 Hollmann MW, Fischer LG, Byford AM, Durieux ME: Local anesthetic inhibition of $\mathrm{ml}$ muscarinic acetylcholine signaling. Anesthesiology 2000;93:497-509.
33 Nietgen GW, Chan CK, Durieux ME: Inhibition of lysophosphatidate signaling by lidocaine and bupivacaine. Anesthesiology 1997; 86:1112-1119.

34 Xiong Z, Bukusoglu C, Strichartz GR: Local anesthetics inhibit the $G$ protein-mediated modulation of $\mathrm{K}^{+}$and $\mathrm{Ca}^{++}$currents in anterior pituitary cells. Mol Pharmacol 1999;55:150158.

35 Ueda N, Kaushal GP, Shah SV: Apoptotic mechanisms in acute renal failure. Am J Med 2000;108:403-415.

36 Meldrum DR, Donnahoo KK: Role of TNF in mediating renal insufficiency following cardiac surgery: Evidence of a post-bypass cardiorenal syndrome. J Surg Res 1999;85:185-199.

37 Donnahoo KK, Shames BD, Harken AH, Meldrum DR: Review article: the role of tumor necrosis factor in renal ischemia-reperfusion injury. J Urol 1999;162:196-203.

38 Groeben H, Silvanus MT, Beste M, Peters J: Both intravenous and inhaled lidocaine attenuate reflex bronchoconstriction but at different plasma concentrations. Am J Respir Crit Care Med 1999;159:530-535.

39 Groeben H, Schwalen A, Irsfeld S, Stieglitz S, Lipfert P, Hopf HB: Intravenous lidocaine and bupivacaine dose-dependently attenuate bronchial hyperreactivity in awake volunteers. Anesthesiology 1996;84:533-539.

40 Yokoyama M, Mizobuchi S, Nagano O, Fujii H, Yamashita M, Hirakawa M: The effects of epidural insertion site and surgical procedure on plasma lidocaine concentration. Anesth Analg 2001;92:470-475.

41 Hodgson PS, Liu SS, Gras TW: Does epidural anesthesia have general anesthetic effects? A prospective, randomized, double-blind, placebo-controlled trial. Anesthesiology 1999;91: 1687-1692.

42 Hollmann MW, Durieux ME: Local anesthetics and the inflammatory response: A new therapeutic indication? Anesthesiology 2000; 93:858-875. 